\title{
Desmame precoce: representações sociais de mães ${ }^{1}$
}

\section{Early weaning: social representations of mothers}

\author{
Destete Precoz: Representaciones Sociales de Madres
}

\author{
Maria Bruno de Carvalho Silva ', Maria Eliéte Batista Moura ", Antonia Oliveira Silva "I
}

\section{RESUMO}

Este estudo tem como objetivo apreender as representações sociais sobre o desmame precoce segundo mães que desmamaram os filhos e explorar os aspectos psicossociais capazes de determinar um diagnóstico sobre o que influencia o ato do desmame. Trata-se de um estudo exploratório orientado pela Teoria das Representações Sociais, realizado em Teresina - Pi. Fizeram parte da amostra 60 mulheres atendidas no pré-natal, por uma equipe de Saúde da Família, que foram submetidos ao Teste de Associação Livre de Palavras e feito a Análise Fatorial de Correspondência. Destas, 20 responderam à entrevista em profundidade. Os dados das entrevistas foram submetidos à análise de conteúdo. O desmame precoce surge com representações ambíguas e complexas onde é possível perceber as contradições entre sentimentos negativos e positivos sobre o ato de amamentar e as implicações na vida e nas relações interpessoais. É necessário, pois, que os programas de incentivo ao aleitamento materno sejam desenvolvidos em consonância com os grupos sociais, visto que não se pode falar em políticas de incentivo ao aleitamento materno eficazes, sem considerar os determinantes do desmame precoce, os quais encontram atrelados às crenças, valores, normas sociais, dentre outros.

Palavras chave: Enfermagem obstétrica; Aleitamento materno; Desmame precoce.

\section{ABSTRACT}

The objective of this study is to apprehend the social representations of early weaning according to mothers who weaned their children and explore the psychosocial aspects capable of determining a diagnosis of what influences the act of weaning. The Social Representation Theory orientated this exploratory study and was carried out in Teresina, PI. Sixty (60) women who were seen in prenatal care by a Family Health team were part of the study. They were given a Free
Word-Association Test and a Correspondence Factor Analysis. Of these, 20 answered the interview in depth. The data of the interviews were submitted to a content analysis. Early weaning emerges with complex and ambiguous representations where it is possible to notice the contradictions between the positive and negative sentiments of breastfeeding and its implications in life and interpersonal relationships. Therefore, it is necessary for the maternal breastfeeding incentive programs to be developed in accordance with the social groups since it is not possible to talk about incentive policies for efficient maternal breastfeeding without considering the determining factors of early weaning which are linked to beliefs, values, social norms among others.

Key words: Obstetric nursing; Maternal breastfeeding; Early weaning.

\section{RESUMEN}

Este estudio tiene como objetivo comprender las representaciones sociales sobre el destete precoz según las madres que destetaron a los hijos y explorar los aspectos psicosociales capaces de determinar un diagnóstico sobre lo qué influencia el acto del destete. Se trata de un estudio exploratorio orientado por la Teoría de las Representaciones Sociales, realizado en Teresina - PI. Hicieron parte de la muestra 60 mujeres atendidas en el período prenatal, por

\footnotetext{
Extraído da Dissertação "Desmame Precoce: representações sociais de mães" Departamento de Enfermagem da Universidade Federal do Piauí - UFPI 2005 1 Mestre em Enfermagem pela Universidade Federal do Piauí - UFPI, Profa da Faculdade NOVAFAPI, Enfermeira do PSF de Teresina - Piauí. maria bruno05@yahoo.com.br

"Doutora em Enfermagem pela Escola de Enfermagem Anna Nery da Universidade Federal do Rio de Janeiro UFRJ, Profa da Graduação e do Mestrado em Enfermagem da UFPI, Coordenadora de Pesquisa e Pós-Graduação da Faculdade NOVAFAPI. posgraduacao@novafapi.com.br

III Doutora em Enfermagem pela USP, Profa Universidade Federal da Paraíba. alfaleda@yahoo.com.br
} 
un equipo de Programa: "Salud de la Familia", que fueron sometidas a la Prueba de Asociación Libre de Palabras y aplicado el Análisis Factorial de Correspondencia. De estas, 20 respondieron a la entrevista en profundidad. Los datos de las entrevistas fueron sometidos a los análisis de contenido. El destete precoz surge con representaciones ambiguas y complejas donde es posible percibir las contradicciones entre sentimientos negativos y positivos sobre el acto de amamantar y las implicaciones en la vida y en las relaciones interpersonales. Es necesario,

\section{NTRODUÇÃO}

O aleitamento materno e sua relação com a diminuição da incidência de doenças infecciosas e da mortalidade infantil têm sido evidenciados em diversos estudos. Em outra perspectiva, têm sido demonstrados os benefícios econômicos diretos e indiretos da amamentação natural quando são considerados os custos com os substitutos do leite materno e os gastos decorrentes com o tratamento das afecções associadas à amamentação artificial (1).

Entretanto, ainda que comprovado o reconhecimento da importância do aleitamento materno, a prevalência do desmame precoce ainda é uma realidade em muitas partes do mundo(2).

No Brasil, a Pesquisa Nacional de Prevalência de Aleitamento Materno nas Capitais Brasileiras e no Distrito Federal, realizada em 1999, constatou que no Nordeste a prevalência do aleitamento materno exclusivo no primeiro mês de vida do bebê era de $50 \%$, aos 120 dias esta proporção caía para $19 \%$ e aos seis meses para $8 \%{ }^{(3)}$.

O desmame precoce tem sido estudado quanto aos fatores relacionados ao lactente e à mãe. Entre estes fatores, está a questão do aleitamento materno vista, principalmente, sob pues, que los programas de incentivo al amamantamiento materno sean desarrollados en consonancia con los grupos sociales, visto que no se puede hablar en políticas de incentivo al amamantamiento materno eficaces, sin considerar los determinantes del destete precoz, quiénes encuentran vinculados a las creencias, valores y normas sociales, entre otros.

Palabras clave: Enfermería obstétrica; Amamantamiento materno; Destete precoz.

o aspecto biologicista, o qual reduz a mulher ao potencial da lactação sem observar o complexo social e cultural que influencia a tomada de decisão de amamentar ${ }^{(4)}$. Destacase a culpa de que a mulher é acometida pela condição de não amamentar seu bebê, diante de motivos variados como, por exemplo, quantidade e qualidade do leite, afecções mamárias, necessidade de trabalhar, entre outros $^{(5)}$.

Neste sentido, observa-se que no cotidiano dos serviços de saúde as mulheres não dispõem de oportunidades de expressarem concretamente os determinantes sócioeconômicos, culturais e psicológicos que contribuíram para o desmame de seus filhos.

A necessidade da adoção de suporte teórico-metodológico que fundamente abordagens que permitam a investigação de aspectos relacionados com os sentimentos, pensamentos e a fala da mulher que amamentou ou desmamou, além dos significados para mãe enquanto mulher e as representações sociais que as têm conduzido ao desmame precoce de seus filhos ${ }^{(6) .}$

Assim, torna-se importante a compreensão da influência do universo cultural na tomada de decisão do ser humano, em que respeitar a pessoa, partilhar com ela saberes e 
costumes é condição essencial para o profissional de saúde na reversão da prática do aleitamento materno, garantindo como conseqüência, a redução do desmame precoce.

Nessa perspectiva, é importante investigar o fenômeno social do desmame precoce subsidiado na teoria das representações sociais, para se explorar os significados e sentidos que influenciam esta prática. Tal teoria pode auxiliar na compreensão de comportamentos e condutas, diante das imagens e conhecimentos associados diretamente ao aleitamento materno, capazes de agirem no desmame precoce, uma vez que muitas mulheres têm condições físicas perfeitas para amamentar, possui conhecimentos técnicos sobre a importância do leite materno e mesmo assim desmamam precocemente seus filhos.

Desta forma, para estudar os sentidos construídos em relação ao desmame precoce, elaborados por mães, fez-se necessário identificar aspectos psico-sociológicos envolvidos considerando as condições de vida de mães que desmamaram, enquanto fenômenos de produção de conhecimentos de sujeitos sociais particulares, a partir da teoria das representações sociais. Estas compreendem "uma modalidade de conhecimento particular que tem por função a elaboração de comportamentos e a comunicação entre os indivíduos". Por isso, "expressa a construção do conhecimento teórico-prático de determinado grupo humano sobre um dado objeto, vivido e construído em circunstâncias históricas precisas"(7).

Os estudos demonstram que ao vivenciarem o desmame precoce, as mulheres apresentam sentimentos diversos que giram em torno da indiferença, de sacrifício, de alívio e prazer, dever cumprido, culpa entre outros. A construção de representações sociais sobre a problemática constitui-se como uma forma de os sujeitos situarem-se frente ás dificuldades vivenciadas $^{(6)}$.

Ao refletir sobre as potencialidades e dificuldades da mulher em amamentar os filhos surgiram questionamentos de como interferir de forma benéfica na evolução natural dos comportamentos dessas mulheres. A partir dessa situação, focalizei como objeto de estudo as representações sociais do desmame precoce segundo mães, por constituir um objeto com relevância cultural e social em relação às práticas e condutas das mulheres que desmamam precocemente os filhos.

Perceber os fatores que evidenciam esse comportamento das mães referente ao desmame e o que há por trás dessa postura constitui um parâmetro com 0 qual os profissionais poderão contribuir. E assim, com o olhar voltado para o objeto de estudo sob a ótica das representações sociais, associado às inquietações vivenciadas e observadas nesse contexto em que se insere esta pesquisa, questiona-se 1. Quais as representações sociais do desmame precoce na concepção de mães que desmamaram precocemente seus filhos? 2. Quais os aspectos psicossociais envolvidos no desmame precoce que influencia a sua prática?

Essas questões conduziram para a estruturação e a delimitação dos principais pontos de convergência e de divergência, aos quais estão submetidas às mulheres que vivenciam o processo do desmame. E com o propósito de responder a esses questionamentos foram elaborados os 
Silva MBC, Moura MEB, Silva AO. Desmame precoce: representações sociais de mães. Revista Eletrônica de Enfermagem [serial on line] 2007 Jan-Abr; 9(1): 31-50. Available from: URL: http://www.fen.ufg.br/revista/v9/n1/v9n1a03.htm

seguintes objetivos para esta investigação: 1 .

Apreender as representações sociais sobre o desmame precoce na concepção de mães que desmamaram precocemente seus filhos. 2. Explorar a partir das representações sociais apreendidas os aspectos psicossociais capazes de determinar um diagnóstico sobre o que influencia o ato do desmame precoce.

Refletindo sobre os programas que tratam de incentivo à amamentação destaca-se como desafio estudar as representações sociais que envolvem o fenômeno do desmame precoce, o que se acredita ser uma lacuna de pesquisa a ser preenchida, dando respostas àqueles que questionam sobre o porquê dos grandes esforços desenvolvidos por diversos profissionais e instituições não alcançarem plenamente seus objetivos.

\section{As representações sociais no contexto do desmame precoce}

Diante de reflexões sobre todos os estudos e ações realizadas em prol da amamentação, concebe-se o homem como um ser sócio-histórico em que sua relação com a natureza é constantemente permeada pelas relações sociais estabelecidas em determinado contexto e período histórico.

Através do estudo sobre a Representação Social da Psicanálise a conceituação e análise de como os indivíduos e grupos são vistos, tanto pelo caráter de comunicação como da expressão e define representações, como uma forma específica de conhecimento que tem como conseqüência, a elaboração de comportamentos e a comunicação entre os indivíduos ${ }^{(7)}$.

Ao refletir um esforço incessante de tornar alguma coisa não-familiar em familiar, e concretizar o abstrato, as representações sociais se estruturam a partir de dois processos que aparecem em fases indissociáveis chamados de objetivação e ancoragem. O surgimento destas fases permite compreender que os processos formadores das representações têm por função atribuir a todo sentido uma figura e toda figura um sentido. A objetivação é, portanto um processo que consiste em uma "operação imaginante e estruturante" pelo qual se dá uma "forma" ao conhecimento acerca do objeto, tornando concreto um conceito abstrato, reproduzido-o numa imagem. Ou seja, é traduzir um esquema apenas conceitual em realidade existente e presente no cotidiano $^{(7)}$.

Por si só, a objetivação não garante a inserção orgânica de uma construção formal do conhecimento. Esta deve está dialeticamente articulada com a ancoragem. Dessa forma assegurando as três funções basilares da representação: a função cognitiva de integração da novidade ou incorporação do estranho ao novo, interpretação da realidade e a função de orientação das condutas e das relações sociais ${ }^{(8)}$.

Sendo assim a ancoragem permite atribuir significação aos objetos/fenômenos estranhos ou desconhecidos que compreendem o sistema particular de categorias dos indivíduos, transformando-os em algo familiar e de utilidade para nossas interações sociais.

Tratar de Representações Sociais, portanto, implica em considerar que, para se adaptar à sua situação social particular e, mais especificamente, para elaborar, planejar e administrar suas estratégias comportamentais pode-se esperar que as mães utilizem não somente as informações captadas na condição 
Silva MBC, Moura MEB, Silva AO. Desmame precoce: representações sociais de mães. Revista Eletrônica de Enfermagem [serial on line] 2007 Jan-Abr; 9(1): 31-50. Available from: URL: http://www.fen.ufg.br/revista/v9/n1/v9n1a03.htm

de nutriz, mas também aquelas já disponíveis no seu sistema particular de categorias as quais são acionadas sempre que necessárias socialmente ${ }^{(9)}$.

\section{ABORDAGEM METODOLÓGICA}

Trata-se de um estudo exploratório e de campo em que se busca apreender os fenômenos de representações sociais relacionados ao objeto do estudo tendo como estratégia de pesquisa 0 conhecimento informal dos sujeitos sociais, para assim explorar aqueles capazes de determinar um diagnóstico sobre os aspectos psicossociais do desmame precoce. ${ }^{(14)}$

O estudo foi desenvolvido na Vila Cidade Leste na cidade de Teresina capital de Piauí e os sujeitos do estudo, moradoras da vila, selecionadas dentre as mulheres que fizeram pré-natal com a equipe no 20 do Programa de Saúde da Família e que desmamaram precocemente seus filhos.

A amostra de 60 mulheres foi definida a partir de um estudo piloto, partindo da concepção de saturação de idéias e considerando a disponibilidade dos sujeitos em participar deste estudo que, após aceitação verbal culminou na assinatura do termo de consentimento livre e esclarecido, obedecendo aos aspectos éticos e legais conforme o Comitê de Ética em Pesquisa da Universidade Federal do Piauí e de acordo com os requisitos da Resolução CNS 196/96, que trata das diretrizes e normas de pesquisa envolvendo seres humanos.

Para coleta de dados foram realizadas vinte entrevistas em profundidades contemplando duas questões de partida: fale sobre o desmame precoce e o que é para você ter desmamado seu filho antes dos seis meses de idade? Com respostas gravadas, dirigidas às mulheres participantes do estudo; as questões norteadoras foram fundamentadas no referencial teórico das Representações Sociais, em que se procurou explorar conteúdos relacionados com as dimensões (atitude, conhecimento/informação e imagens), processos e funções das Representações Sociais; testadas, a partir de um estudo-piloto realizado na primeira etapa da pesquisa, com objetivo de fundamentar $o$ roteiro da entrevista.

O procedimento analítico e o tratamento das informações se deram com base em um plano geral de análise e tratamento, utilizandose a Técnica de Análise de Conteúdo Temático Categorial. O tipo de análise selecionado requer algumas considerações teóricas e para tanto, é conveniente entender que a análise de conteúdo se aplica à análise de textos escritos ou de qualquer comunicação, verbal ou gestual, dentre um conjunto de técnicas de análise de comunicação que contém informações sobre o comportamento humano apresentado em uma fonte documental ${ }^{(10)}$.

As entrevistas foram submetidas a análise de conteúdo temática(10) ${ }^{(10}$ guindo as etapas: leitura flutuantes; constituição do corpus (sessenta entrevistas); seleção das unidades de contexto (considerada paragrafo); seleção das unidades de registro (frase); recorte; codificação; processo de categorização, apreendidas cinco categorias temáticas empíricas: Aspectos culturais do desmame precoce; Manifestações sobre o desmame; Posicionamento frente à amamentação; Efeitos da Amamentação e Sentimentos; Interpretação; Inferência e 
Validação dos dados. Os dados obtidos a partir do Teste de Associação Livre de Palavras com as palavra-estímulos: amamentar; leite materno e desmame precoce, após organização e preparo do banco de dados, as informações obtidas foram processadas pelo software TriDeux Mots ${ }^{(11)}$; indicado para tratamento de questões abertas e fechadas e interpretados por meio da Análise Fatorial de Correspondência (AFC). A AFC avalia as correlações existentes entre diferentes grupos de caracteres, colocando em evidência os campos semânticos definidos pelas palavras associadas ao estímulo e à sua contribuição para a construção dos fatores ou eixos que constituem o plano fatorial. É ideal para explicar as representações sociais obtidas através do Teste de Associação Livre de Palavras, porque enfoca as variáveis fixas ou sócio-demográficas e as variáveis ativas ou de opiniões, que se confrontam e se revelam, graficamente, na representação do plano fatorial. O referido teste compreende um instrumento que permite ao entrevistado, a partir dos estímulos indutores, evocarem respostas de conteúdos afetivos e cognitivoavaliativos.

\section{O DESMAME PRECOCE COMO CONHECIMENTO SOCI ALMENTE ELABORADO}

O fenômeno do desmame precoce pela ótica das Representações Sociais possibilita edificação de conceitos, explicações e afirmações que se originam no cotidiano através das comunicações e do conhecimento socialmente elaborado e compartilhado(7). Pautado nessa abordagem, explicitada pela teoria, a realização deste estudo teve como elemento determinante o discurso das mães que vivenciaram ou vivenciam no seu cotidiano, problemas relacionados com a amamentação.

No que concerne à elaboração do conhecimento do senso comum, apreendeu-se representações sociais que vão desde os aspectos culturais e de crenças a uma pluralidade de descrições que giraram em torno de manifestações explicativas/justificadoras, socioeconômicas, psicossociais a orgânicas/físicas; posicionamentos favoráveis, desfavoráveis e neutros; efeitos da amamentação (anatômicos, psico-afetivos e fisiológicos) e dos sentimentos (positivos e negativos), vivenciados pelas mulheres, sujeitos deste estudo.

Nos agrupamentos das cinco categorias temáticas e das subcategorias, foram consideradas, durante 0 procedimento analítico, suas inter-relações, identificando as divergências e consensos que nelas se mostram, sendo que no decorrer da análise, pôde-se observar como cada categoria está relacionada umas com as outras. Os resultados serão apresentados exemplificando-se as falas por meio das unidades de análise temáticas em que não são identificadas as referidas falas por códigos e sim agrupadas semanticamente os recortes dos sujeitos conforme preconiza a técnica selecionada.

\section{Categoria A - Aspectos culturais do desmame precoce}

Nesta categoria verifica-se que os sujeitos do estudo têm suas subjetividades, crenças, tradições, valores ancorados em experiências anteriores delas próprias de 
Silva MBC, Moura MEB, Silva AO. Desmame precoce: representações sociais de mães. Revista Eletrônica de Enfermagem [serial on line] 2007 Jan-Abr; 9(1): 31-50. Available from: URL: http://www.fen.ufg. br/revista/v9/n1/v9n1a03.htm

familiares e vizinhos. Dai à necessidade, que impõem o entendimento das questões culturais na influência do modo de ser do homem e, é claro, do da mulher no ato de amamentar.

Evidencia-se uma maior freqüência, as unidades temáticas, em que os sujeitos atribuem uma importância de destaque para os lactogogos, considerados de excelência na produção de leite. Assim, para essas mães, além do aumento da ingesta de líquidos é também necessário comer bem para que aumente a produção de leite: [..quando eu tomava caldo que dava uma hora e meia eu já tinha leite [...] quando eu cheguei da maternidade eu tomei uma copada de caldo de cana o povo diz que faz fazer mais leite [...] eu tomo muito liquido, caldo de cana, água de rapadura e bastante suco $[\ldots]$

Percebe-se que são inúmeros os cardápios, dietas e regras que permeiam as crenças alimentares da lactante. Em relação ao aumento da ingestão de líquidos, recomenda-se que a nutriz receba, através de sua alimentação, grande quantidade de água, glicídios, proteínas, lipídios, sais minerais e vitaminas, elementos que serão utilizados para a formação do leite, com a finalidade de não desfalcar suas reservas orgânicas ${ }^{(12)}$.

Em relação à composição dos alimentos, observa-se que a dieta materna e o estado nutricional pouco influenciam sobre o conteúdo de macronutrientes (carboidratos, proteínas e lipídios) e também sobre a concentração de energia no leite materno. Entretanto a quantidade pode diminuir se não houver nutrientes disponíveis para a glândula mamária, sem que haja alteração significativa quanto a sua composição(13). Contudo, um dos fatores que influencia a decisão das mulheres de adotarem ou não a amamentação, prendese ao fato de acreditarem não dispor de alimentação suficiente ou os alimentos disponíveis apresentarem pouca qualidade para produzir o leite necessário para amamentar os filhos, como se pode verificar nos exemplos: [...] a mãe com fome não tem leite para o filho[...] eu acho que eu não tinha leite porque não me alimentava direito[...] eu só sei porque meu leite era pouco porque eu comia pouco[...]

Por outro lado, dados relatados com freqüência que constituem referências ao leite materno, por ser avaliado como pouco ou fraco, associados às interpretações das manifestações de comportamento do bebê (choro) como indicadores de fome, tanto pela mãe como para toda a família caracterizandose por reflexos de experiências anteriores vivenciadas pelo grupo social: [...]uns dizem, ah! o leite é muito fraco, só não sustenta [...] e muita gente diz que leite do peito é fraco não mata a fome [...] o leite é fraco eu escuto muito isso aqui na comunidade [...] eu ainda dou o peito mas não mata a fome o leite é pouco e fraco[...]

Para compreender tais relatos é importante destacar que o leite fraco, compreende uma das construções sociais mais utilizadas como explicações para o abandono da amamentação. Evidencia-se o fato de que mulheres de várias culturas fazem referência ao leite fraco como razão para o desmame. Contudo, do ponto de vista biológico não existe leite fraco e que são raras as intercorrências que impossibilitam a amamentação(14).

Dessa forma, a herança que o homem carrega, não é apenas a genética que transmite as características físicas, mas 
Silva MBC, Moura MEB, Silva AO. Desmame precoce: representações sociais de mães. Revista Eletrônica de Enfermagem [serial on line] 2007 Jan-Abr; 9(1): 31-50. Available from: URL: http://www.fen.ufg. br/revista/v9/n1/v9n1a03.htm

também, a cultural que veicula costumes hábitos e valores que contribuem para construção do saber do homem. Assim as crenças fazem parte desta construção social determinando a conduta dessas mães da decisão de amamentar.

Os textos das entrevistadas demonstram claramente o posicionamento sociocultural (tradição/valores) que se sobrepõe à determinação biológica e se confirma nas experiências anteriores de mães, avós, sogras e vizinhas, ressaltando a importância da vivência como indispensável para o sucesso do aleitamento materno: [...]a mamãe dizia: o que sustenta menino é o mingau $[\ldots]$ não se cria menino sem dar chá [...] minha mãe sempre dar as orientações [...] no meu tempo ninguém amamentava assim não, era no mingau com sebo de rim de boi[...]. Percebese que a figura da mãe da nutriz ainda exerce a função de orientadora com maior credibilidade, se comparada com as orientações de profissionais, recebidas pela gestante por ocasião do pré-natal.

A introdução de outros alimentos líquidos ou sólidos ilustram as concepções observáveis no cotidiano dessas mulheres, evidenciando-se a relação gordura/saúde e o valor do estereótipo "bebê gordinho", como determinantes do julgamento de se estar ou não cuidando bem do filho, por seus pares em seu grupo social: [...] a filha da vizinha é só no peito e é uma bolinha [...] ela tá gordinha e tão bonitinha, por isso é que eu acho que tem criança que o leite mata a fome e tem criança que não, a minha só no peito não engorda [...] criança sadia é criança gorda [...]

O processo de vida cotidiana é tão envolvente que absorve quase totalmente as pessoas, e poucas são as que conseguem superar e viver conscientes as próprias emoções, sentimentos e desejos ${ }^{(6)}$. Apesar desse processo afetar todos os indivíduos, a atitude de conformismo e de não enfrentamento é mais comum entre as mulheres pela sua formação e poucas são aquelas que conseguem transpor os condicionamentos sociais como os que foram revelados nas frases: [...] ]eu sabia que o leite só, era bom, mas minha mãe dizia: mesmo eu criei todo mundo e era assim mamava pouco e eu dava papa e era tudo gordo[...] minha avó e até a vizinha dizia: dá mingau essa menina! ai eu taquei mingau[...]

Dessa forma, o aleitamento materno deixa de ser instintivo e biológico, tornando-se um comportamento social e mutável, conforme o decurso da história e os costumes de um povo. O aleitamento materno ou a recusa raramente constitui um ato individual e consciente, estando preso à aprovação do grupo social ${ }^{(15)}$. Representa, pois, uma escolha individual que se desenvolve dentro de um contexto social influenciado e construído pela sociedade que carrega uma herança sóciocultural, determinando diferentes significados do aleitamento materno para a mulher.

\section{Categoria B - Manifestações sobre o desmame}

As mulheres entrevistadas procuravam mostrar como lutaram para conseguir desempenhar "o papel de mãe" e realizar com sucesso a amamentação, porém em alguns momentos sentiam-se também julgadas, exploradas e desamparadas: [...] as pessoas não sabiam minha situação e ficavam me julgando [...] eu acho ruim quando fica todo 
mundo me criticando [...] foi falta de apoio [...] ninguém me ajudava [...] ninguém me apoiava $[\ldots]$

Para essas mulheres, as manifestações sobre o desmame estão associadas à ansiedade, angústias e desespero diante da decisão que terá de tomar, de forma solitária, como responsáveis únicas que são, para que a amamentação aconteça com sucesso, pois conforme os relatos as mães ficavam com receio dos julgamentos que poderiam surgir em decorrência do seu fracasso. Além disso, reconhecem que é atribuído à elas, a responsabilidade pela manutenção da saúde dos seus filhos e ao mesmo tempo percebem as dificuldades que os outros têm de compreender a necessidade de apoio para um bom desempenho da amamentação.

Por outro lado, a ansiedade, a opinião e os conselhos das pessoas próximas, companheiro, mãe, sogra, irmãs, vizinhos e de profissionais de saúde com os quais a mulher tem contato, surgem como elementos significativos nesse processo, as seguintes falas: [...]as pessoas e os doutor diziam que ela largou o peito porque eu dei alimento pra ela [...] eles falavam, porque eles não sabiam o que eu passava [...] por que o médico disse que ela tinha que ficar até os seis meses no peito e ela não ficou [...].

O estresse provocado pela situação e a intervenção de familiares e amigos somados à insegurança e à dúvida se relacionam com a baixa produção de leite, uma vez que culminam com a síntese de peptídoes supressores nas células alveolares da glândula mamária que impedem o processo de síntese do leite ${ }^{(16)}$.
Como conseqüência, as agentes sociais sentem-se compelidas a aceitar a intervenção das pessoas e assumem posições de acordo com as interações sociais mantidas, contribuindo pelo sucesso ou não da amamentação. Isso porque a amamentação e o desmame fazem parte do contexto ativo e dinâmico da coletividade, em que as comunicações e os comportamentos conduzem a um processo de interações sociais e formação de condutas.

As manifestações sobre o desmame demonstraram as dificuldades que as mães têm em lidar com o choro da criança, associando-o à fome e à concepção de que o leite é pouco e fraco, e por isso insuficiente para saciá-lo. A não observação da saída concreta do leite e a manifestação de insatisfação da criança com o choro freqüente colocam em dúvida a condição de o leite materno estar suprindo adequadamente as necessidades da criança, conforme unidades de análise a seguir: [...] quando eu espremia sai pouco leite, mas não como eu via nas outra mulheres [...] molhava a blusa bem pouquinho [...] se ela passar o dia todo sem mamar é o dia todo sem o peito encher [...] eu acho que ela chorava porque ela sentia fome [...] ele é muito guloso [...] dava, dava o peito e ele não calava $[\ldots]$

Uma vez estabelecida a lactação, a glândula mamária fica sobre o controle autócrino, que congrega os reflexos maternos de produção e ejeção do leite ${ }^{(17)}$. Sendo assim, do ponto de vista da fisiologia da amamentação, a lactação envolve a ação de hormônios, cuja concentração no sangue depende da estimulação de terminais nervosos do complexo mamilo-areolar pelo lactente 
Silva MBC, Moura MEB, Silva AO. Desmame precoce: representações sociais de mães. Revista Eletrônica de Enfermagem [serial on line] 2007 Jan-Abr; 9(1): 31-50. Available from: URL: http://www.fen.ufg.br/revista/v9/n1/v9n1a03.htm

através da sucção, bem como, de estímulos visuais e auditivos.

Quanto ao volume do leite, a sua produção varia de forma diretamente proporcional ao número de mamadas e não tem relação alguma com o tempo de duração das mesmas e o reflexo de ejeção ou de retirada do leite depende da ação da ocitocina.

Dessa forma é possível compreender as manifestações dessas mães diante comportamentos adotados em relação ao aleitamento materno que as conduzem a elaboração de conhecimentos possíveis de determinar o desmame precoce, visto que, são produzidos numa interdependência do sujeito/objeto/interação social.

Dentre as explicações e justificativas que emergiram, destacam-se as alegações maternas de atribuir à criança os motivos pelos quais não foi capaz de iniciar e manter a amamentação pelo período que gostaria. Os relatos centram-se na recusa por parte da criança como o principal argumento apresentado por essas mães: [...] não sei o que foi, ele é que não quis mais o peito [...] ela não quer mamar [...] meu filho não aceitou o peito [...] meu filho não gosta de mamar [...] ela não quis ai eu não forcei mais [...] pegava o bico do peito e botava na boca dela e ela não queria mais $[\ldots]$

A elaboração de explicações/justificativas desse conhecimento ancora-se em dados considerados e interpretados pela mulher como sendo concretos e visíveis, irrefutáveis, que justificam as suas ações e novos comportamentos adotados. A decisão pela amamentação está na dependência da mulher, porém ela é levada a justificar suas ações, conforme o significado que seus atos têm e o grupo a que pertença. Esses são aspectos que possibilitam compreender, porque a mulher tende a buscar sempre explicações para a conduta assumida diante do fenômeno do desmame precoce.

\section{Categoria C - Posicionamento Frente à Amamentação}

O posicionamento favorável ao leite materno e ao ato de amamentar são objetivados por essas mulheres como: bom, importante, indispensável, fundamental e necessário. É possível se compreender a partir desses dados revelados como favorável, a ênfase dada pelas mães ao valor da amamentação e à disposição em amamentar em que as mesmas constroem o valor prático de amamentar como o melhor para a criança, respondendo aos apelos da comunidade e apropriando-se do discurso dos profissionais, reinterpretando-os e relacionando a amamentação a uma boa condição de saúde e desenvolvimento para a criança. A seguir as falas que corroboram com estas afirmativas. [...] mas eu sei a importância do leite [...] que o leite do peito é bom, o melhor para criança, é necessário [...] as pessoas diziam minha irmã tira o peito desse menino! minha sogra dizia: dar outra coisa pra esse menino, mas eu não ia pela cabeça dos outros eu sei que o leite do peito é fundamental [...]

Os dados são compatíveis com as evocações encontrados nesse estudo através da a análise fatorial de correspondência (AFC) e ilustram as concepções observáveis no cotidiano dessas mulheres. As representações encontram-se associadas a um conteúdo cognitivo que reconhece o valor nutricional do leite materno e a sua importância por 
Silva MBC, Moura MEB, Silva AO. Desmame precoce: representações sociais de mães. Revista Eletrônica de Enfermagem [serial on line] 2007 Jan-Abr; 9(1): 31-50. Available from: URL: http://www.fen.ufg.br/revista/v9/n1/v9n1a03.htm

proporcionar uma boa condição de saúde e desenvolvimento da criança e denota a incorporação das informações veiculadas através dos programas de incentivo ao aleitamento materno.

Por outro, conteúdo das entrevistas também denota posicionamentos desfavoráveis das mães frente à amamentação como nos exemplos das falas apreendidas e a seguir: [...] eu acho que as crianças ficam desnutridas não é porque deixam de mamar, e sim, porque as mães não cuidam, eu acho assim [...] ela não mama, é gordinha e sadia [...] sei que ta ai bonito grande e gordo e não mamou [...]

Mo entanto ficou evidente a superioridade de posicionamentos favoráveis construídas sobre amamentação e percebe-se a função justificadora na elaboração dessas construções sociais, em que as mães apresentam em seus discursos manifestações que lhes garantam uma imagem positiva diante da opção de amamentar que se sobrepõe ao posicionamento conteúdo desfavorável ou neutro.

\section{Categoria D - Efeitos da amamentação}

A representação dos efeitos da amamentação, na concepção das mães, está vinculada de maneira significativa à saúde da criança e a sua importância para a prevenção das doenças e o controle do crescimento e desenvolvimento saudável: [...] saúde, porque a criança fica forte e não adoece [...] faz bem para a criança [...] a criança amamentada tem saúde [...] ficava forte e enquanto ela mamava não gripou $[. .$.

Outro fator que está associado aos efeitos fisiológicos da amamentação, a partir das alegações maternas, diz respeito aos sintomas de fraqueza e tontura Esses elementos se constituem em dados significativos na avaliação que a mãe faz das condições físicas e de sua capacidade em atender as necessidades do filho, bem como, das condições que ela se percebe para amamentar, como nas falas: [...] eu era todo tempo fraca [...] aí eu ficava fraca [...] eu me sentia fraca [...] eu não conseguia amamentar ele direito, porque eu me sentia fraca $[. .$.$] era tontura e ele mamava muito [...]$

As representações sociais exteriorizadas nessa subcategoria sinalizam, para a apreensão de conteúdos científicos a cerca do aleitamento materno, as quais de certa forma são reinterpretadas à luz do conhecimento do senso comum.

O que apreendeu-se da análise dos dados desta categoria, é que a maioria das mães representou, através dessas falas, o aleitamento materno como uma prática difícil e desgastante, que envolve preocupação, ansiedade, nervosismo, irritação e insegurança.

Através da informação e conhecimento, elaborados pelos sujeitos do estudo no seu grupo social, "o peito caído", configura-se como uma das construções sociais mais freqüentes no que se refere aos efeitos de comprometimento anatômico pela amamentação, visto que das dezessete unidades de análise que compõe a subcategoria corpo/anatômico, treze fazem referência à mama caída. A seguir algumas falas que reforçam essa idéia: $[\ldots]$ eu amamento e meus peitos caíram só um pouquinho [...] eu não dei porque meus peitos iam cair [...] por que caía os peitos [...] tem 
mãe que diz que não quer dar de mamar porque cai os peitos[...]

Observa-se nos dados acima, que o processo de amamentar, é para essas mães e para o seu grupo social um componente importante no comprometimento anatômico das mamas contribuindo para alteração da estética do corpo da mulher após lactação

É importante entender que a alteração mamária ocorre na mulher por diferentes fatores, dentre eles a gravidez, pois as mamas aumentam de tamanho e peso a partir do momento da gestação, especialmente em mulheres com maior tendência à flacidez. Não é o fato do bebê sugar que deixa a mama caída, mas a constituição anatômica de cada mulher e a alteração ocorrida por conta da gravidez Por outro lato, os mamilos, podem ficar um pouco mais salientes devido a sucção e a aréola fica mais escura, no entanto retorna a cor natural após a amamentação(18).

\section{Categoria E - Sentimentos}

A quinta categoria denominada sentimentos faz alusão aos aspectos negativos e positivos da amamentação. Nos sentimentos vivenciados pelas mães, observa-se a presença de componentes polarizados entre o sofrimento e o prazer. Dessa forma, o ato de amamentar se apresenta como uma vivência permeada por conflitos e contradições, que são expressos por sentimentos diversos. A exaltação de sentimentos prazerosos ao amamentar o filho é esperada pelo meio social, no entanto é comum a coexistência de ambigüidade de sentimentos frente à amamentação. Portanto, os sentimentos negativos nem sempre são explícitos para quem o vivencia, certamente por não serem condizentes ao perfil de mãe que o seu grupo social espera ${ }^{(14)}$.

O ato de amamentar, para as mães, é considerado como sentimento negativo os relatos que produzem sensações desconfortantes e desagradáveis, conforme se identifica nas falas a seguir: [...] é muito cansativo $[. .$.$] vem o sono e a gente não pode$ dormir é desconfortável [...] a menina chorava e eu ficava aperreadinha [...] com muita dúvida [...] me sentia culpada [...] ficava a decisão pra $\operatorname{mim}[\ldots]$

O prazer em amamentar está associado também à percepção das mães de que o leite é bom e importante para alimentação do filho, aumenta os laços mãe-filho e ainda deixa a mãe orgulhosa, satisfeita por poder suprir as necessidades do bebê com segurança e sem conflitos.

Assim, as representações sociais do desmame precoce, apreendidas nos agrupamentos das categorias revelaram no decorrer do procedimento analítico suas interrelações quanto ao nível de informação circulante entre os sujeitos do estudo identificando assim, as divergências e consensos.

\section{CAMPO DE REPRESENTAÇÃO OU I MAGEM DO DESMAME PRECOCE}

Os dados obtidos a partir do Teste de Associação Livre de Palavras e processados pelo software Tri-Deux Mots deram, origem a um conjunto de 949 palavras como respostas para os estímulos/indutores amamentar, leite materno e desmame precoce destas, $123 \mathrm{com}$ significados diferentes. Esta redução deu-se, pela formação dos dicionários, através do agrupamento pela similaridade semântica 
Silva MBC, Moura MEB, Silva AO. Desmame precoce: representações sociais de mães. Revista Eletrônica de Enfermagem [serial on line] 2007 Jan-Abr; 9(1): 31-50. Available from: URL: http://www.fen.ufg. br/revista/v9/n1/v9n1a03.htm

existente entre as palavras, por exemplo, expressões como: importante, indispensável e fundamenta, foram reduzidas a uma única palavra, "importante", para se referir a amamentar.

Através do Gráfico 1, pode-se observar o conteúdo das representações ou imagens sobre o desmame precoce, tornando-se possível a partir da objetivação configurada no campo representacional, fazer a leitura e interpretação das modalidades ou variáveis de opinião pelas palavras evocadas ou representações, correlacionando-as com as variáveis fixas ou variáveis socio-demográficas (idade, estado civil, religião e escolaridade) organizadas de oposta, segundo os eixos ou fatores (F1 e F2). 
Gráfico 1. Representaç̃o gráfica do plano fatorial sobre o Desmame Precoce

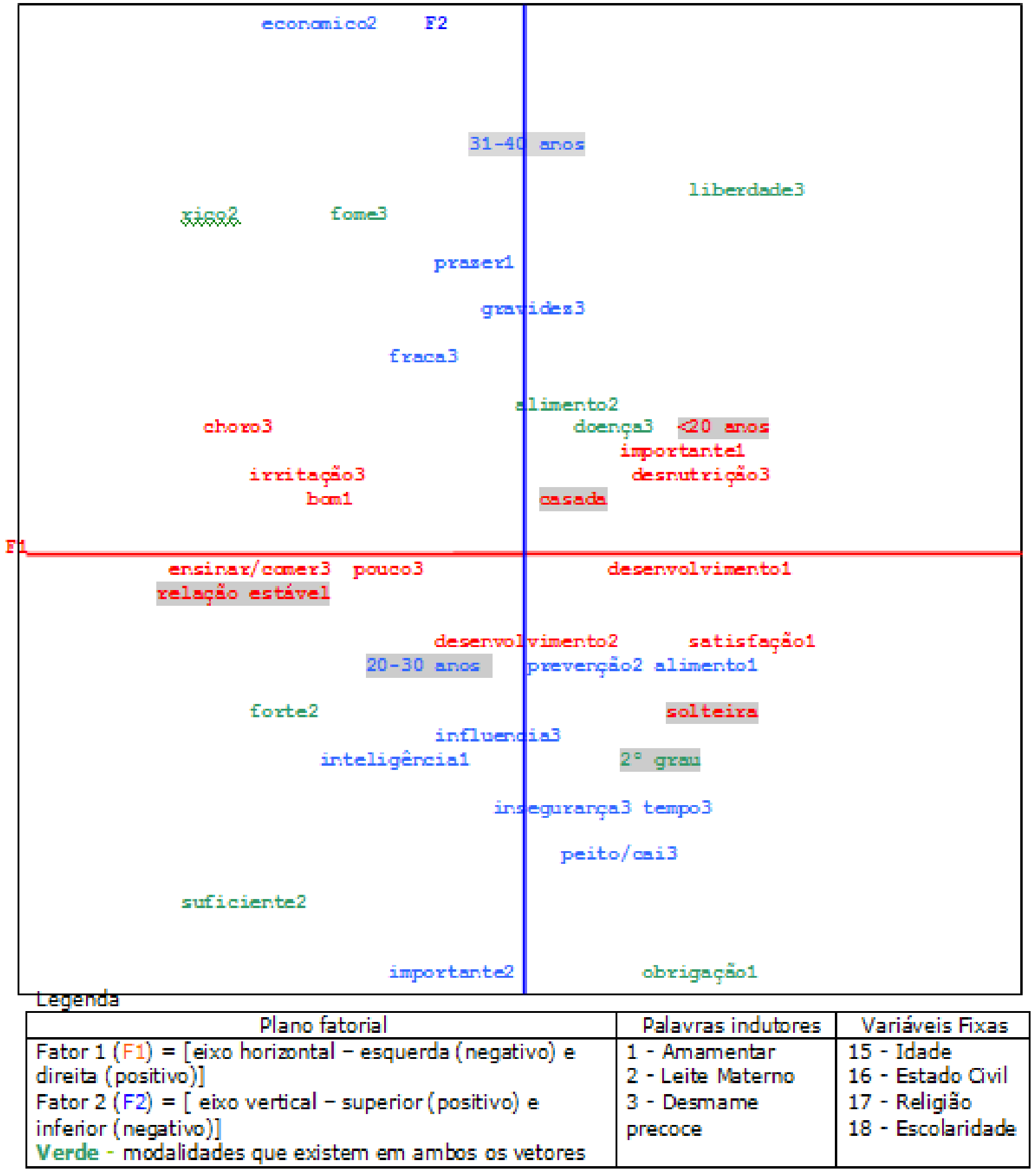

Salientam-se na cor vermelha as modalidades que compõem o fator $\mathrm{F} 1$; na cor azul estão às modalidades que contribuíram com o fator $\mathrm{F} 2$ e em verde as modalidades comuns aos dois fatores. E destacadas com a cor cinza estão as variáveis sócio-demográficas que contribuíram para formação dos respectivos fatores.

Os dados apresentados, a partir do gráfico 1 , obedecendo à distribuição das modalidades no campo representacional, começa pelas palavras que se encontram no 
Silva MBC, Moura MEB, Silva AO. Desmame precoce: representações sociais de mães. Revista Eletrônica de Enfermagem [serial on line] 2007 Jan-Abr; 9(1): 31-50. Available from: URL: http://www.fen.ufg.br/revista/v9/n1/v9n1a03.htm

lado, esquerdo e direito do F1 (eixo horizontal vermelho) e em seguida as palavras que se encontram no lado inferior e lado superior do F2 (eixo vertical azul).

\section{Fator 1 - lado esquerdo}

Destaca-se no gráfico, do lado esquerdo do fator 1 (eixo horizontal vermelho) um conjunto das representações sociais sobre amamentar, leite materno e desmame precoce, elaboradas por mulheres que vivenciam uma relação estável.

Sendo assim, segundo esse grupo de sujeitos, amamentar é sinonímia de bom. Essa palavra surgiu do agrupamento de palavras com similaridade semântica destacadas quis sejam: faz bem, faz bem para a criança, melhor e boa alimentação. Através dessas modalidades a mãe reconhece $a$ ato de amamentar como uma experiência boa, além de promover o bem estar do filho. Percebe-se, neste bojo, a presença da função identidária e justificadora na elaboração das representações das mães, que procuram manter a imagem positiva de sua prática justificando o posicionamento favorável frente ao aleitamento materno.

A representação do leite materno, pelas mães com um posicionamento favorável, descritos como: forte, rico e suficiente. Essa representações apresentam-se fortemente vinculada aos aspectos benéficos da alimentação do bebê, por proporcionar uma boa condição de saúde e desenvolvimento para a criança. As mulheres constroem o valor do leite materno como o melhor para o seu filho, tendo por base o reconhecimento das qualidades nutricionais e quantidade suficiente para atender as demandas da criança.
Ainda nesse mesmo eixo, as mulheres de relação estável objetivam o desmame precoce com conteúdos negativos como: choro, fome, irritação, pouco e aprender/comer. Essas modalidades exaltam o choro da criança, corroborando com os achados das entrevistas desse mesmo estudo, que relaciona as dificuldades que as mães tem em lidar com o choro da criança, associando-o à fome e à concepção de que o leite é pouco, portanto insuficiente para saciá-lo, o que certamente levaria a irritação da criança, da própria mãe e de toda a família. Uma outra variável referida centra-se na necessidade da criança aprender/comer logo nos primeiros dias de vida, por acreditarem que a criança só mamando até os seis meses não aprendem comer outros alimentos.

\section{Fator 1 - lado direito}

Por outro, no lado oposto do mesmo fator (F1), observa-se a delimitação do agrupamento das representações sociais sobre os mesmo estímulos amamentar, leite materno e desmame precoce, construídas por mães casadas ou solteiras situadas na faixa etária menores de vinte anos com o segundo grau completo.

Neste lado do eixo, o ato de amamentar é manifestado pelas mães um campo representacional correspondente a importante, satisfação, desenvolvimento e obrigação. Desse modo, em relação a esse estímulo indutor, configuram-se contradições, em que se percebe um posicionamento de ambigüidade, visto que, as mães ao mesmo tempo em que referem modalidades de conteúdo favorável, como importante e satisfação, por outro, associam a prática de 
amamentar vivenciada no seu cotidiano, muitas vezes, a um fardo que terá que carregar, aqui representado pela variável, obrigação. A amamentação pode ser percebida pela mãe como uma prática que demanda prazer e satisfação, porém para outras poderão senti-la como prática desconfortável e conflituosa, tornando-se uma atividade de cunho obrigatório que certamente contribuirá para formação de conduta, levando ao fenômeno do desmame precoce.

O leite materno é expresso pelas mães, nesse fator, no lado direito, assim como no lado esquerdo com uma conotação favorável, através do campo semântico representado pelas palavras: desenvolvimento e alimento. Dessa forma, o leite materno pode ser avaliado, pelos sujeitos sociais, como o alimento que apresenta inúmeras vantagens oferecidas ao crescimento e desenvolvimento saudável da criança.

Enquanto que desmame precoce é representado como sinonímia de desnutrição, doença e liberdade. As manifestações demonstram o conhecimento que as mães têm sobre os efeitos do desmame precoce por reconhecerem que a falta do leite materno contribuem para o surgimento de doenças prevalentes da infância e para promoção da desnutrição infantil. Contudo, a palavra liberdade denota a necessidade das mães de sentirem-se mais livres para suas atividades ocupacionais e de lazer.

\section{Fator 2 - lado inferior}

No fator 2 (eixo vertical azul) no lado inferior do gráfico 1 , destaca-se as representações sobre amamentar, leite materno e desmame precoce, elaboradas por mulheres na faixa etária entre 20 a 30 anos e que possuem o segundo grau completo.

As modalidades correspondentes às variáveis de opinião evocadas por essas mães em resposta ao estímulo amamentar, são representadas pelas palavras: alimento, inteligência e obrigação. Existe nesse fator correlações de similaridade semântica com as evocações do fator (F1) lado direito, principalmente por apresentar a palavra obrigação, reforçando portanto as considerações feitas acima.

Em relação ao leite materno, as mulheres destacam as palavras: importante, suficiente, forte e prevenção, quando se referem a esse estímulo. O valor do leite materno revela-se como favorável em todas as manifestações, nas quais as mães demonstram conhecer as propriedades e a influência que o leite do peito exerce sobre a saúde da criança.

Já o desmame precoce, é descrito em um campo representacional com evidências da função justificadora das representações sociais, pois é manifestado como: tempo, peito/cai, insegurança e influências. A apropriação das vivências e experiências do cotidiano individual e coletivo dessas mães permite, então, representar o desmame precoce como conseqüência de inúmeros fatores associados aos aspectos psicossociais, socio-culturais e físicos.

\section{Fator 2 - lado superior}

No fator 2 (eixo vertical azul) no lado superior do gráfico 1 , encontram-se as objetivações de amamentar, leite materno e desmame precoce, construídas por mulheres com faixa etária entre 31 a 40 anos. 
Silva MBC, Moura MEB, Silva AO. Desmame precoce: representações sociais de mães. Revista Eletrônica de Enfermagem [serial on line] 2007 Jan-Abr; 9(1): 31-50. Available from: URL: http://www.fen.ufg. br/revista/v9/n1/v9n1a03.htm

No que se refere a palavra amamentar os sujeitos contribuíram com uma única modalidade: prazer. Essas mães vivenciam a amamentação como uma prática que pode ser sentida pelas nutrizes como capazes de lhes proporcionar prazer e gratificação. A exaltação dos sentimentos prazerosos é o esperado pelo meio social, no entanto, porém é comum a coexistência de sentimentos ambíguos diante do ato de amamentar. O desprazer nem sempre é explícito para quem o vivencia, por não serem condizentes ao perfil de mãe, esperado pelo seu grupo social ${ }^{(14)}$.

Para representar leite materno, no lado superior do gráfico, as mães destacam as palavras: alimento, rico e econômico, como resposta a esse estimulo indutor. Em consonância com as análises feitas até então sobre as palavras evocadas, no campo representacional do gráfico, em atendimento ao estímulo leite materno, da mesma forma, nesse lado do fator (F2), é representado por palavras de conteúdo favorável, trazendo nesse contexto, a representação da riqueza do leite do peito do ponto de vista nutricional.

Ainda em relação ao mesmo fator, as mulheres apresentam como sinonímia do desmame precoce, as variáveis: fraca, fome, gravidez, doença e liberdade. Essas modalidades corroboram com os achados na análise de conteúdo das entrevistas, mencionados nesse estudo, que referem a fome e a fraqueza sofrida pelas mães, intimamente relacionadas a necessidade de uma alimentação materna suficiente e de boa qualidade, para que a mesma possa sentir-se em condições de amamentar.

Observa-se ao final dessa análise uma íntima relação entre as representações sociais produzidas pelos sujeitos e apreendidas através das entrevistas e as que emergiram a partir do teste de Associação Livre de Palavras, visto, que todas as modalidades evocadas no segundo instrumento de coleta encontram-se presentes nas unidades de registro dos conteúdos das entrevistas. Sendo assim, refletindo-se sobre as técnicas de apreensão dos dados utilizadas nesse estudo, constata-se que se revelaram excelentes recursos de captação das representações sociais do desmame precoce e funcionaram como instrumentos complementares de identificação de elementos importantes à compreensão do objeto de estudo.

Vale ressaltar que os discursos das categorias analisadas e a análise fatorial de correspondência referem que as representações sociais, enquanto teorias práticas sobre determinado objeto ou problemas sociais específicos e importantes na vida dos grupos, alimentam e são produzidos numa interdependência do sujeito/objeto/interação social. Dessa forma é possível apreender os aspectos psicossociais, presentes nas culturais, nas manifestações, nos posicionamentos nos sentimentos e nas evocações desses sujeitos, como componentes sociais determinantes do desmame precoce visto que, contribuem para orientação de condutas e construção do conhecimento em relação ao fenômeno social do estudo ${ }^{(8)}$.

\begin{tabular}{llrr}
\multicolumn{1}{c}{ Embora se } & verifique & um \\
compartilhamento & & consensual & das \\
representações sociais & produzidas & pelos
\end{tabular}
sujeitos, este por si só não explica a sua denominação social. O que as torna sociais, e é a sua produção coletiva revestida de funcionalidade especifica, de orientação de 
Silva MBC, Moura MEB, Silva AO. Desmame precoce: representações sociais de mães. Revista Eletrônica de Enfermagem [serial on line] 2007 Jan-Abr; 9(1): 31-50. Available from: URL: http://www.fen.ufg.br/revista/v9/n1/v9n1a03.htm

condutas, resolução de problemas e formalização das relações sociais ${ }^{(19)}$.

\section{CONSI DERAÇÕES FI NAIS}

Neste estudo procurou-se a partir da apreensão das representações sociais do desmame precoce construídas por mães, explorar os aspectos psicossociais envolvidos nesse processo como determinantes ou não da adesão das mães à prática do aleitamento materno.

O desmame precoce como objeto social, constituiu o foco deste estudo, a partir do qual as mães puderam explicitar as representações sociais através dos instrumentos de pesquisa, entrevista em profundidade e o teste de Associação Livre de Palavras, que possibilitaram diferentes formas de se apreender as representações sociais. Além disso, observou-se que os resultados de acordo com cada instrumento mostraram-se equivalentes e funcionaram como técnicas complementares entre si, na apreensão dos conteúdos, possibilitando um aprofundamento na compreensão de elementos importantes na construção do desmame precoce, além de conduzir a interpretações mais fidedignas.

As entrevistas submetidas à análise de conteúdo possibilitaram identificar um aparato de informações que serviu de suporte a análise realizada e foi complementada pela análise fatorial de correspondência da associação livre de palavras sendo, pois, configuradas as semelhanças entre os dados apreendidos nos dois tratamentos realizados.

O fenômeno do desmame precoce se revelou com representações ambíguas e complexas, nas quais se percebem contradições entre sentimentos positivos e negativos e posicionamentos favoráveis e desfavoráveis que se interpõe aos atributos culturais, socioeconômicos e psicossociais, contribuindo para as concepções que a mulher tem de si, do ato de amamentar e das implicações, nas emoções e nas relações sociais.

Em consonância com os achados da análise de conteúdo das entrevistas, constatou-se, através da análise fatorial de correspondência, que as mães reconhecem o leite materno como beneficente para o bebê e demonstram conhecer as propriedades e a influência que a lactação exerce sobre a saúde da criança ao evocarem palavras/frases como: bom, importante, forte, suficiente, traz saúde e evita desnutrição além de vivenciarem a amamentação como uma prática que desperta prazer, favorece momentos de alegria e satisfação para o bebê e para a mãe.

Por outro, as concepções sobre o desmame precoce foram objetivadas através das expressões: doença, leite pouco, fome (da mãe ou da criança), estado de fraqueza, uma nova gravidez, mastite, peito/caído, pouco tempo, influência de familiares e visinhos, necessidade de trabalhar e chorava muito, que si interpõe à carência das mães de se sentirem mais livres e ao reconhecimento da amamentação como uma atividade de cunho obrigatório.

Tratar de representações sociais do desmame precoce, implica em considerar que a mulher, para elaborar, planejar e administrar suas estratégias comportamentais diante da decisão ou não de amamentar, pode-se esperar que essas mães, incorporem não somente as informações veiculadas através dos programas de incentivo ao aleitamento 
Silva MBC, Moura MEB, Silva AO. Desmame precoce: representações sociais de mães. Revista Eletrônica de Enfermagem [serial on line] 2007 Jan-Abr; 9(1): 31-50. Available from: URL: http://www.fen.ufg. br/revista/v9/n1/v9n1a03.htm

materno, mas também aquelas já disponíveis no sistema particular de categorias, as quais são acionadas sempre que necessárias socialmente.

É necessário, pois, ressaltar que a implementação dos programas de incentivo ao aleitamento materno, deva ser desenvolvida em consonância com as comunidades, sem desprezar o fato de o grupo social contribuir e exercer domínio na orientação de condutas, além de compreender que assistência e apoio ao aleitamento materno não pode estar restrito aos aspectos biológicos, incorporando o discurso dos profissionais, onde as mulheres não conseguem expressar os reais motivos pelos quais encontram-se envolvidas e que certamente contribui para o desmame precoce dos filhos.

À medida que são objetivadas as representações sociais do desmame, ancoradas nos aspectos psicológicos, sociais, sócioculturais e biológicos, evidencia-se um conflito entre as propostas dos programas de incentivo ao aleitamento materno que focalizam predominantemente os aspectos biológicos, epidemiológicos, econômicos e quase nunca do ponto de vista social e psicológico. Portanto, constata-se que os profissionais desconhecem a complexidade da comunicação humana, dificultando o alcance dos objetivos propostos e transformando-se em atividades rotineiras e estereotipadas. Nesse sentido não se pode falar em políticas de incentivo ao aleitamento materno eficazes, sem considerar toda uma gama de determinantes do desmame precoce que se encontram atrelados às crenças, valores, normas sociais, dentre outros ${ }^{(20)}$.

Há de se encontrar um caminho que conduza à compatibilização dos aspectos biológicos e dos determinantes sociais, na interface da amamentação, que contemple a pluralidade dialética de fatores que interferem nos espaços sociais onde circulam saberes e práticas de diferentes visões de mundo, ideologias, crenças e atitudes relativas ao processo da amamentação. Deve-se para tanto abrir alicerces que possa dar lugar às mudanças de condutas dos sujeitos envolvidos o processo além de permitir aos profissionais que partilhem desse contexto sócio-histórico e psicossocial, conhecendo os reais motivos que levam as mulheres a abandonarem a lactação e, assim, apreender as diferentes maneiras como as representações sociais do desmame precoce são elaboradas e vivenciadas a partir das reações das mães que não conseguem levar adiante a prática do aleitamento materno exclusivo.

\section{REFERÊNCIAS}

1. Ministério da Saúde (BR). Norma brasileira de comercialização de alimentos para lactentes e crianças de primeira infância, bicos, chupeta e mamadeiras. Brasília (DF): Ministério da Saúde; 2002.

2. Organização Mundial de Saúde (OMS). Proteção, promoção e apoio ao aleitamento materno: o papel especial dos serviços materno-infantis. Declaração Conjunta OMS/UNICEF. Genebra: Editora da OMS; 1989.

3. Ministério da Saúde (BR) Prevalência de aleitamento materno nas capitais brasileiras e no Distrito Federal: relatório preliminar. Brasília (DF); 2001.

4. Silva IA. O significado de amamentar para a mulher. [Doutorado]. São Paulo (SP): Escola de Enfermagem da Universidade de São Paulo; 1994.

5. Ramos CV, Almeida J A G. Amamentação, desmame, mulher, relação biológico-social. J ornal de Pediatria 2003; 79 (5): 385-390.

6. Almeida MS. Sentimentos femininos: o significado do desmame precoce para mulheres. Texto e Contexto - Enfermagem 1997 jan-abril; 6(1): 25-32.

7. Moscovici S. A representação social da psicanálise. Rio de Janeiro (RJ): Zahar; 1978. 
8. Jodelet D. Representações sociais: um domínio em expansão. In: Jodelet D. (Org), As representações sociais. Rio de Janeiro $(R J)$ : UERJ ; 2001.

9. Berger PI, Luckmannn, T. A Construção Social da Realidade. Petrópolis (RJ): Vozes; 1991.

10. Bardin L. Análise de conteúdo. Lisboa. (PT): Edições 70; 1977.

11. Cibois UFR. Tri-deux mots - Versão 2.2. Paris (FR): Sciences Sociales; 1995.

12. Ornellas A, Ornellas $\mathrm{IH}$. Alimentação da lactante. In: Ornellas A, Ornellas A. Alimentação da criança. São Paulo (SP): Atheneu; 1983.

13. Organização Mundial de Saúde (OMS). Fatores de saúde que podem interferir na amamentação. In: Organização Mundial da Saúde (OMS). Alimentação Infantis bases fisiológicas. São Paulo (SP): IBFAN Brasil e Instituto de Saúde, OMS, OPAS, e UNICEF Brasil; 1994.

14. Nakano AMS. O aleitamento materno no cotidiano feminino. [ Doutorado]. Ribeirão Preto/SP: Escola de Enfermagem de Ribeirão Preto/Universidade de São Paulo; 1996.

15. Silva AM. Amamentação: fardo ou desejo? Estudo histórico social dos deveres e práticas sobre aleitamento na sociedade brasileira. [Dissertação]. Ribeirão Preto (SP): Faculdade de Medicina de Ribeirão Preto/USP; 1990.

16. Almeida JAG. Amamentação: um híbrido natureza-cultura. Rio de Janeiro (RJ): Editora Fiocruz; 2002.

17. Akre J. Alimentação infantil: bases fisiológicas. São Paulo (SP): Instituto de Saúde; 1989.

18. Machado MT. Amamentação consciente. Fortaleza/CE [serial on line] 2000 [cited 2005 set 05] Available from: $<$ http://www. aleitamento.org.br>

19. Vala J. Representações sociais para uma psicologia do pensamento social. In: Vala, J, Monteiro, M. B. Metodologia em ciências sociais. Lisboa (PT): Calouste/Gulbenkian; 1993.

20. Tura LFR. A AIDS: repensando a prevenção. In: Tura LFR, Moreira ASP. Saúde e representações sociais. João Pessoa (PB): Universitária; 2004.

Artigo recebido em 26.12.06

Aprovado para publicação em 30.04.07 